\title{
CONSUMER BEHAVIOUR DURING ONLINE GROCERY SHOPPING
}

\author{
Gabriela Hanus ${ }^{1}$
}

\begin{abstract}
Today consumers can buy almost any product using the Internet. Online nutritional and grocery shopping is becoming increasingly popular. The aim of this paper is to present the conditions of online grocery shopping and consumers' attitude towards buying food via the Internet based. The assessment is based on secondary information sources. With online grocery supermarkets there are no limitations connected with localization and opening hours, and consumers have access to a large range of stores and products online across the world. The most important advantages of online shopping are convenience and time saving, while the most significant disadvantages for consumers involve the risk of incorrectly valuating some products and apprehension about the selection and handling of perishables, such as vegetables, eggs, and meat products.
\end{abstract}

JEL Classification Numbers: O35, DOI: http://dx.doi.org/10.12955/cbup.v4.737

UDC Classification: 304

Keywords: Grocery shopping, e-consumer, e-commerce, electronic retailing.

\section{Introduction}

The role of consumers in the market is changing with market development. The definition of consumer originates from the Latin word, consumens, which means to purchase (goods or services) for direct use or ownership (Rybowska, 2010). In the field of theory and practice of consumption research, particular attention is given to 'consumer behavior' and its determinants. According to Salomon: "consumer behavior is a process that includes pre-consumption, consumption and post-consumption phases. Consumer behavior is related to more than commercial issues, it also involves interactions with nonprofit organizations and government institutions. Consumers play several roles in the process of selecting, buying and using goods, services and experiences" (Solomon, 2013, p.2).

E-commerce is becoming ever more popular among companies that are interested in wider market penetration, as well as among consumers who look for optimal methods of buying goods and having access to information about such goods (Karpińska-Krakowiak, 2014). According to the statistical office of the European Union, the number of consumers aged 16 to 74 having purchased goods and services for personal use through the Internet has incessantly risen, from 30\% in 2007 to 53\% in 2015 (Eurostat, 2015). Most e-consumers are content with their shopping: 70\% claimed they do not have any problems with purchasing online. In 2015, the most popular products bought online were clothes and sporting goods (chosen by $60 \%$ of e-buyers), accommodation and travel (52\%), and household goods and toys $(41 \%)$. The largest number of e-buyers is found in the United Kingdom ( $81 \%$ of all persons aged 16 to 74 order items online), Denmark (79\%), and Luxemburg (78\%). Online shopping is more popular among younger generations (16-44 years old) than those older (45-74 years old; Eurostat, 2015). Consumers gain proficiency in the virtual world. There are many new products on the Internet that were previously available in a limited way, such as fresh food products. It has been estimated by various authorities that grocery online shopping is becoming increasingly popular among consumers. There are numerous online supermarkets available, for example: Alma, Piotr i Paweł, Tesco, Auchan, E. Leclerc, frisko.pl, dodomku.pl, where consumers can find almost all nutritional products that they need (Karpińska-Krakowiak, 2014).

The aim of this paper is to present the conditions of online grocery shopping and consumers' attitude towards buying food using the Internet, with research based on secondary information sources. Hence, in this article, specific differences between online and conventional grocery shopping are presented, and advantages and disadvantages of online grocery shopping from consumers' points of view are indicated.

\section{The Specification of Online Grocery Shopping}

Buying through the Internet is one of the most dynamically developing forms of trade (Ramus \& Nielsen, 2005). Consumers in developed countries, for instance in the USA or in some countries in

\footnotetext{
${ }^{1}$ Gabriela Hanus, University of Economics in Katowice, Katowice, Poland, gabriela.hanus@edu.uekat.pl
} 
Europe, have used the Internet for everyday shopping and the popularity of purchasing grocery online is increasing annually in both the USA and Western Europe (Bianchi \& Andrews, 2012). As a result, there has been increasing interest in understanding consumers' behavior with online grocery shopping. Managers of Internet grocery shops look for answers for several questions associated with consumers' behavior, because this information helps to create an effective design and marketing strategy in the online shopping environment and provides a competitive advantage (Andrews \& Currim, 2004; Rohm \& Swaminathan, 2004). The specification of online grocery shopping is extraordinary with consumers' behavior and attitudes in this area different to that expressed when buying more complicated products. When buying nutrition articles, consumers are not as involved in purchasing them as when they buy other products. The social and financial risk is lower, while routine, frequency, and repeatability of nutrition purchases are higher, so that consumers have more opportunities to verify and check products. These conditions are often the reason for unplanned and impulsive purchases (Walters, Toase, Hong \& Mackel, 2005). The marketing specialists use numerous ways to persuade clients to buy their products, especially when consumers do not really need them.

The electronic channels of food distribution have significant influence on conditions of consumer purchasing decisions. In grocery e-shops, customers can buy anything, at any time, and from every place; there are no limitations connected with localization and opening hours. The purchasing process is shorter than in traditional supermarkets. Consumers have had some experience with traditional shops, and thus, they do not need to spend so much time in 'getting to know' the assortment, compared with their first visit at a traditional shop. The assortment of grocery products online is similar to those offered in traditional trading places. At times, there is a lower range of brands for one product category, which leads consumers to buy retailer own-brands products. There is no large difference in prices among electronic supermarkets (about 7\% including delivery costs). However, the individual stores have different policies for organizing delivery. For example, in some stores there is no possibility of being able to buy and then receive the product on the same day, and additionally, when it is holiday season, clients need to request delivery service at least two weeks in advance (Karpińska-Krakowiak, 2014).

\section{Consumers' Attitude Towards Online Grocery Shopping}

For consumers to buy food online, they need to make several decisions including the selection of shopping network and place, financial matters, compiling shopping lists or choosing product brands. In literature, two approaches of analyzing consumers' decisions can be found. The first is associated with the rationality of consumer behavior. According to this theory, consumers behave rationally, which means that they aim to maximize their satisfaction or their utility function (in economic terms). They are guided by order of precedence created by a social group to which they belong (in sociological terms) and look for logical arguments in the evaluation of their own actions (in philosophical and psychological terms). Their behavior is characterized by prudence, purposefulness, internal consistency, and calculation of alternatives. The second group of theoretical concepts is associated with irrationality of people's decisions. In the framework of this theory, there are many factors that limit the most optimal purchasing choice, e.g., uncertainty, risk, limited time, and access to information. The consumers' behavior is characterized by contingency, emotionality, impulsivity, unconsciousness, or hastiness. As several studies have shown, consumers make rational decisions towards goods of high interest and indicate a relatively high proportion of impulse and emotion in the case of purchasing often-used products, e.g., food. Many surveyed consumers admit that their food buying decisions are impulsive, emotional, and reckless. There are various sales techniques that generate immediate impulsive shopping, e.g., sales, coupons, additional discounts with a short expiry date, or free services such as delivery (Karpińska-Krakowiak, 2014).

Several studies have attempted to define an e-shopper's profile, especially in demographic and psychographic terms. There have been indications that Internet consumers earn more money that nonInternet shoppers and are less risk averse, and more innovative and impulsive. These shoppers prefer that online shops are always open and find shopping from home is relaxing, easy, and time saving (Ramus \& Nielsen, 2005).

Consumers claim that the most important determinant and advantage of online business success is the convenience of online shopping. It is noted that there are various types of online shopping 
convenience, such as access, search, evaluation, transaction, and possession convenience. Access convenience means that consumers can shop at any time and from locations such as home or office; they do not even have to leave their rooms. They can avoid crowds, serve no waiting times, and have access to products that are not normally available in everyday shops. Search convenience is related to the opportunity for researching and comparing products without physically visiting stores. Several improvements have recently been made with regard to the evaluation of shopping online convenience. The changes are mainly concerning the enhancement of descriptions of products by means of applying better presentation features, e.g., graphics and videos. In addition, peer evaluation systems boost the efficacy of buying products through the Internet. Such customer review systems make the decision to buy not only fast and efficient, but also effortless. Transaction convenience is associated with simplicity and ease of online payment. The online sellers know that complicated payment methods often cause consumers to resign from purchasing at the last minute. Possession convenience means that online shopping reduces consumers' effort and time spent on purchasing products. Consumers do not have to leave their places to shop or wait in long queues (Jiang, Yang \& Jun 2013). Consumers claim that in some cases it is difficult to shop at a traditional grocery supermarket, because of reasons, such as lack of a car, time, or physical strength to carry heavy items (Huang \& Oppewal, 2006). As the research shows, the most significant convenience for consumers is that of enabling them to order groceries from home and then having these delivered, and this helps save time due to less visits to traditional retail stores (Verhoef \& Langerak, 2001; Ramus \& Nielsen, 2005). The advantage of online grocery shopping for consumers is that they have access to a large range of stores and products from across the world (Ramus \& Nielsen, 2005). It is worth noting that a greater impact on the consumer's preferences to shop for groceries online is possibly the saving of travel time more than the extent of delivery charges (Huang \& Oppewal, 2006).

However, there are some disadvantages of electronic grocery shopping. One is associated with the risk of incorrect assessment of some products. Some online product images are of the low quality or there is even no image of the product, what makes it more difficult to assess the actual size, weight and value of it. There is a lower probability for consumers buying new products online with there being no opportunity to taste and smell the product during shop presentation (Karpińska-Krakowiak, 2014). It is also noted that some personal needs are limited during shopping using the Internet, e. g., consumers need sensory stimulation and physically activity, and they are fond of learning while shopping. A similar situation relates to social needs, e.g., consumers need to experience social interaction, to feel the pleasure of bargaining during shopping, and communicating with other consumers. Nevertheless, there is a possibility of joining discussion groups on the Internet, so that e-buyers can communicate with others and this can partly substitute for traditional shopping pleasure. Other examples of the disadvantage of electronic grocery shopping might be the high costs of searching or the waiting time for delivery (Verhoef \& Langerak, 2001). An important determinant of consumers' intention to buy groceries through the Internet relates to their fear about selection and handling of perishables, such as vegetables, eggs, and meat products. Buying fresh products is connected with knowing product expiry dates, which is impossible online (Galante, López \& Monroe, 2013; Toomey \& Wysocki, 2009). Generally, prices on the Internet are considered to be lower on one hand, but on the other hand econsumers can miss out on special bargains in the traditional shops. Online shoppers are also worried about the problem of returning products that are ruined or not matching expectations. It should be noted that many consumers enjoy conventional shopping. They acknowledge that shopping trips to the supermarket have a social lure. Many families and friends find shopping an interesting way of spending time together.

The results of the analysis of non-Internet shoppers show that some have objections to online systems of payment. These doubt that payment systems are sufficiently safe and do not want to share personal information, e.g., credit card details, while making payments online (Ramus \& Nielsen, 2005).

As several studies show, most surveyed respondents are quite satisfied with their online grocery shopping experiences. There are several groups of consumers who have unique reasons for shopping online. One specific group is mothers with young children in the household. Online shopping allows them to buy nutritional foods without taking young children to the supermarket or needing to seek someone to care for their children while they shop. The availability of online grocery shopping also helps consumers avoid appeals of their children to buy sweets. The next group, which is very positive 
about online grocery shopping, is consumers with physical disabilities, who appreciate that they can shop for food through the Internet without problems of lifting and carrying groceries. It should be noted that an ageing population exists in many countries and minor physical limitations will probably increase, and this could mean a higher demand for home shopping and delivery services (Morganosky \& Cude, 2000).

\section{Conclusion}

E-commerce is one of the most dynamically growing forms of trade. Consumers can buy almost anything through the Internet. Several studies show that there is a significantly increasing popularity of online grocery shopping. There are numerous differences between online and traditional shopping in this area. In grocery e-shops, consumers avoid the limitations associated with localization or opening hours. They can buy products more conveniently and faster. However, the most important advantage of online grocery shopping in the consumers' opinion is the possibility of saving time (they do not have to leave home and wait in long queues). Though, online grocery shopping poses some risk in incorrectly valuating certain products because of the inadequate presentation on the website. In addition, online shoppers forego the opportunity of managing their choices according to the expiry dates of products. It should be noted that some personal needs are limited during online shopping, such as sensory stimulation or social needs. Generally, research shows that consumers are satisfied with their online grocery shopping experiences and their attitudes towards it are positive. Nevertheless, there are still many consumers who experience apprehension about electronic payments and sharing their personal information.

\section{References}

Andrews, R. L., \& Currim, I. S. (2004). Behavioural differences between consumers attracted to shopping online versus traditional supermarkets: implications for enterprise design and marketing strategy. Int. J. Internet Marketing and Advertising, 1(1), 38-61.

Bianchi, C., \& Andrews, L. (2012). Risk, trust, and consumer online purchasing behaviour: A Chilean perspective. International Marketing Review, 29 (3), 253-276.

Eurostat (2015). E-commerce by individuals, Retrieved from http://ec.europa.eu/eurostat/documents/2995521/ 7103356 /411122015-AP-EN.pdf/276b6a7c-69a6-45ce-b6bf-488e975a8f5d (19.02.2016)

Galante, N., López, E. G., \& Monroe, S. (2013). The future of online grocery in Europe. McKinsey \& Company, 22-31.

Huang, Y., \& Oppewal, H. (2006). Why consumers hesitate to shop online. An experimental choice analysis of grocery shopping and the role of delivery fees. International Journal of Retail \& Distribution Management 34 (4/5), 334-353.

Karpińska-Krakowiak, M. (2014). Consumer behavior while grocery shopping on-line — research propositions. Marketing i Rynek 6, 20-26.

Jiang, L., Yang, Z., \& Jun, M. (2013). Measuring consumer perceptions of online shopping convenience. Journal of Service Management, 24 (2), 191-214.

Morganosky, M. \& Cude, B. (2000). Consumer response to online grocery shopping. International Journal of Retail \& Distribution Management, 28(1), 17-26.

Ramus, K., \& Nielsen, N. (2005). Online grocery retailing: what do consumers think? Internet Research 15(3), 335-352.

Rohm, A. J., \& Swaminathan, V. (2004). A Typology of Online Shoppers Based on Shopping Motivations. Journal of Business Research, 57, 748-757.

Rybowska, A. (2010). Internet shops client's shopping behaviour. Research Journal, Gdynia Maritime University, 65, 23.

Solomon, M. R. (2013). Consumer Behavior, Buying, having being, 2.

Toomey, A. C., \& Wysocki, A.F. (2009). Distinguishing between Traditional and Online Retailing: Evaluating E-commerce with Respect to the Food System. Food and Resource Economics Department, 1-4.

Walters, D. M., Toase, M. C., Hong, P., \& Mackel, M. (2005). A Survey into Consumer Experiences and Attitudes Towards Online Grocery Shopping in The UK. IADIS International Conference on WWW/Internet 2005, 236-244.

Verhoef, P., \& Langerak, F. (2001). Possible determinants of consumers' adoption of electronic grocery shopping in the Netherlands. Journal of Retailing and Consumer Services, 8, 275-285. 